\title{
Quando os sistemas públicos de saúde são notícia: uma análise comparativa da cobertura jornalista no Brasil e na Espanha
}

\author{
When public health systems are news: a comparative analysis \\ of the journalistic coverage in Brazil and Spain
}

Andrea Langbecker (https://orcid.org/0000-0001-5292-8220) ${ }^{1}$

Marcelo Eduardo Pfeiffer Castellanos (https://orcid.org/0000-0002-4977-5574) ${ }^{1}$

Daniel Catalán-Matamoros (https://orcid.org/0000-0002-3086-6812) ${ }^{2}$
${ }^{1}$ Instituto de Saúde

Coletiva, Universidade Federal da Bahia. R. Basílio da Gama s/n, Canela. 40110040 Salvador BA Brasil. alangbecker@hotmail.com ${ }^{2}$ Departamento de Comunicación, Universidad Carlos III de Madrid.

Madrid España.

\begin{abstract}
This study aimed to undertake a comparative analysis of the journalistic coverage of the National Health System (SUS) by "Folha de São Paulo", and the National Health System (SNS) by "El Pais". This qualitative study was anchored in the news values theory focusing on selection and construction news values and content analysis. All the contents published during 2013 of both newspapers were analyzed. "Folha" brought 88 covers, with 100 cover stories in total, and "El Pais" had 37 covers and 39 cover stories. "Folha's" coverage focused on the "Mais Médicos" program, while most of the news in El Pais focused on the privatization of the Spanish public health system. The most important news value in both was related to government. As a second category, in "Folha", controversy prevailed, focusing on the clash between the Federal Councils of Medicine and the Ministry of Health. Impact was the second most popular category in the Spanish newspaper. Concerning the news values of construction, we found that the newspapers used diverse resources. "Folha" adopted simplification in its approach, whereas "El País" invested in personalization and dramatization to sensitize readers with accounts of users, where the background was often the privatization process of health care services.
\end{abstract}

Key words National Health System, Unified Health System, Health journalism, News-values
Resumo Este trabalho teve como objetivo analisar, de forma comparativa, a cobertura jornalística sobre o Sistema Único de Saúde (SUS), na "Folha de São Paulo", e sobre o Sistema Nacional de Salud (SNS), no "El País". O presente estudo, de cunho qualitativo, ancorou-se nos valores-notícia de seleção e de construção e em análise de conteúdo. Foram analisadas as capas publicadas em 2013 de ambos os jornais. A Folha trouxe 88 capas, com 100 chamadas no total e, no El País, foram 37 capas e 39 chamadas. A cobertura da "Folha" centrou-se no programa Mais Médicos; e, no "El País", a maioria das notícias enfocou a privatização da saúde pública espanhola. O valor-notícia mais presente nos dois foi governo. Como segunda categoria, na Folha, prevaleceu a polêmica, enfocando o embate que se formou entre os conselhos federais de medicina e o Ministério da Saúde. No caso do diário espanhol, a segunda categoria mais presente foi o impacto. Em relação aos valores-notícia de construção, as estratégias foram diversas. A "Folha" lançou mão da simplificação em relação à abordagem adotada, e o "El País" investiu na personalização e na dramatização para sensibilizar os leitores ao trazer relatos dos usuários em que, em muitos casos, o pano de fundo era o processo de privatização da saúde.

Palavras-chave Sistema Nacional de Salud, Sistema Único de Saúde, Jornalismo em saúde, Valores-notícia 


\section{Introdução}

Apesar das diferenças socioeconômicas, históricas e culturais entre o Brasil e a Espanha, é possível identificar semelhanças no processo de reforma sanitária que, nesses dois países, ocorreu durante o período de redemocratização após anos de ditadura ${ }^{1}$.

No caso brasileiro, com a Constituição de 1988, a saúde passa a ser reconhecida como um direito social, cabendo ao Estado a sua garantia $^{2}$. Criava-se, assim, o Sistema Único de Saúde (SUS), que tem como um dos seus princípios a universalidade, o que garante constitucionalmente a todos os brasileiros o acesso ao sistema ${ }^{3}$.

O SUS avançou muito e transformou-se em um grande projeto público com milhões de beneficiados. Como frisam Paim et al. ${ }^{4}$, entretanto, ainda enfrenta grandes desafios: a expansão do setor privado tem gerado resultados negativos na equidade, no acesso aos serviços de saúde e nas condiçõos de saúde.

Na Espanha, desde a constituição de 1978, a proteção da saúde é um direito fundamental do cidadão, cabendo aos poderes públicos organizar o Sistema Nacional de Salud (SNS) 5 . Entretanto, a crise econômica internacional de 2009 afetou as políticas sociais espanholas, o que levou a uma reforma no SNS, marcada por "pressões de abertura do sistema público ao capital privado, por meio de medidas privatizantes e de restrição do acesso"', resultando na publicação do Decreto n ${ }^{\circ}$ 16/2012. Conhecida como 'apartheid sanitário', tal normativa representou um passo atrás no que se refere ao direito à saúde, uma ruptura com a ideia de universalidade e igualdade, com perdas graves de direitos ${ }^{7,8}$.

É possível perceber que ambos os sistemas enfrentam desafios parecidos, como o de garantir a universalidade, sobreviver aos cortes no financiamento e concorrer com a expansão dos seguros privados, retrocessos que também vêm ocorrendo em outros países, como Itália, Grécia e Portugal, em decorrência de crises econômica ou política9.

Nesse contexto, buscamos refletir como e quando os sistemas públicos brasileiro e espanhol são notícia. Em relação à cobertura midiática brasileira há poucos trabalhos ${ }^{10-14}$. Em linhas gerais, esses estudos constataram que as notícias enfocaram os períodos de dificuldades e crises do SUS. No caso espanhol, há poucos estudos cujo sistema público seja o enfoque prioritário ${ }^{15,16}$; em outros, o sistema é uma das variáveis investigadas, entre outras, relacionadas à saúde/saúde pública ${ }^{17-19}$.
Tomando como parâmetro os que analisaram alguma dimensão sobre a produção de notícias - assumindo aqui ser este nosso interesse - verificamos que esse enfoque é ainda mais restrito. Nos referimos aos estudos que analisaram os critérios de noticiabilidade, em específico os valores-notícia, presentes na cobertura jornalística sobre esses sistemas de saúde. Esses valores referem-se às características ou aos atributos presentes nos fatos que os potencializariam a candidatos à notícia ${ }^{20,21}$.

Não encontramos trabalhos que trouxessem essa perspectiva sobre o SUS. Em relação ao SNS, García-Latorre e Gobantes-Bilbao ${ }^{22}$ destacaram que questões sobre a saúde pública espanhola contam com um alto valor-notícia no contexto do Estado de Bem-Estar Social.

O presente estudo teve como objetivo analisar a cobertura jornalística da Folha de São Paulo e do El País sobre o Sistema Único de Saúde e o Sistema Nacional de Salud, respectivamente, tendo como base os critérios de noticiabilidade. Comparar poderia trazer à tona os elementos convergentes e divergentes da cobertura jornalística sobre essa temática.

\section{Material e métodos}

O presente estudo, de cunho qualitativo, realizou uma pesquisa documental, cuja metodologia utilizada foi a análise de conteúdo com base em Bardin $^{23}$ e como referencial teórico os aportes da teoria da notícia e dos critérios de noticiabilida$\mathrm{de}^{21,24-26}$.

Para escolher os meios estudados, foi utilizado como critério o jornal de referência em cada país ${ }^{21}$ o que nos levou a selecionar a Folha de São Paulo e o El País. Ambos vêm ocupando, durante anos, as primeiras posições de diários de interesse geral com maior circulação. Distinguem-se como veículos que buscam se diferenciar - como standard de qualidade - em relação aos seus concorrentes e perante seus públicos, como, por exemplo, serem pioneiros na utilização do ombudsman (o representante dos leitores no jornal) e o uso de manual de redação e estilo, que é de acesso ao público, trazendo o perfil e as normas do jornal.

Criada em 1921, o jornal brasileiro, com sede em São Paulo, pertence ao Grupo Folha, um dos principais conglomerados de mídia no país. Em relação à sua linha editorial, define-se como um jornal crítico, apartidário, moderno e pluralista ${ }^{27}$. Fundado em 1976, El País, com sede em Madri, 
pertence ao maior grupo de comunicação da Espanha, o Prisa. Define-se como independente, nacional, mas com vocação global e, especialmente, latino-americana ${ }^{28}$.

Foram verificadas as 365 capas, publicadas em 2013, selecionando todas as chamadas relacionadas ao Sistema Único de Saúde, na Folha de São Paulo, e ao Sistema Nacional de Salud, no El País. Buscou-se visualmente nas capas, respectivo a cada jornal, referências às palavras SUS/SNS, Sistema Único de Saúde/Sistema Nacional de Salud, sistema público/sistema sanitário, saúde pública/salud publica, e/ou referência a órgãos públicos de saúde e seus representantes e/ou a programas, serviços e ações dessas instituições, bem como referências aos profissionais de saúde e usuários. As chamadas foram classificadas em categorias a fim de caracterizar quais temas ganharam destaque na primeira página, nos mostrando o que realmente foi considerado relevante para a imprensa investigada.

Para analisar os critérios de noticiabilidade, as chamadas foram classificadas por meio de categorias previamente estabelecidas, baseandose nas tipificações de valores-notícia de seleção elaboradas por Silva ${ }^{20}$ (Quadro 1) e nos valoresnotícia de construção elaborados por Traquina ${ }^{21}$ (Quadro 2). Os primeiros permitem "identificar similaridades e diferenciações na seleção ou hierarquização de acontecimentos em diversos veículos da imprensa, possibilitando percepções históricas e culturais sobre o processo produtivo das notícias"20. Já os valores-notícia de construção ${ }^{21}$ são utilizados durante a elaboração da notícia e estão relacionadas às escolhas de "como fazer" 11,26 . Funcionam como "linhas-guia para a apresentação do material, sugerindo [...] o que deve ser prioritário na construção do acontecimento como notícia"21.

Chamadas são títulos que sintetizam as principais notícias que o jornal seleciona para compor a capa, conforme os seus critérios de importância e interesse. Geralmente são sucintas e atrativas dependendo do perfil de cada veículo. Uma capa é composta pela manchete (título principal trazendo a notícia que é destaque naquela edição, geralmente acompanhada de um subtítulo, de um resumo explicativo, de fotos ou de elementos gráficos) e por outros títulos menores que também podem estar acompanhamentos desses elementos ${ }^{29}$.

Assumimos como uma limitação deste estudo não analisar, por questões operacionais, outros critérios de noticiabilidade, como o julgamento dos jornalistas, relacionamento com as fontes e os públicos e questões ainda de ordem política, econômica, social e histórica ${ }^{20}$.

Em relação ao período investigado, optou-se por 2013 por ser o ano em que a constituição federal brasileira - que deu as bases legais para a garantia do direito à saúde - completou 25 anos. Ao mesmo tempo, esse período foi marcado por manifestações nas ruas, as "jornadas de junho", em que a saúde foi apontada como uma prioridade, tendo como resposta do governo a criação do Programa Mais Médicos ${ }^{30}$. Na Espanha, 2013 também foi palco de manifestações nas ruas, conhecidas como Marea Blanca, contrárias às mudanças desencadeadas pela reforma no SNS, ocorridas um ano antes, e em defesa da saúde pública.

\section{Resultados}

Verificamos quais fatos foram escolhidos para ganhar as capas, construindo uma realidade editada sobre os sistemas de saúde. Para Baccega ${ }^{31}$, esse processo é metonímico - a parte pelo todo. O que os meios de comunicação nos oferecem é uma edição do mundo.

A Folha foi quem trouxe mais notícias na primeira página relacionadas ao SUS, contabilizando 88 capas, se comparada com o El País, que apresentou a seus leitores 35 capas, durante o ano de 2013, sobre o SNS. Na Folha, as 88 capas contaram com 100 chamadas, sendo que 14 foram manchetes; em 11 edições, houve mais de uma chamada relacionada ao tema por capa. No caso do El País, as 37 capas contaram com 39 chamadas, sendo duas manchetes; em apenas duas edições, houve mais de uma chamada por capa. Na maioria dos dias investigados, não houve chamadas na Folha $(75,90 \%)$ e no El País $(89,32 \%)$, evidenciando que esse tema - quando olhado em sua distribuição anual - foi tratado de forma periférica, recebendo pouco destaque na primeira página.

As notícias que ganharam as capas da Folha centraram-se no Programa Mais Médicos, representando $48 \%$ do total de chamadas (Tabela 1). A maioria enfocou a participação de médicos estrangeiros, com ênfase para os cubanos, como na chamada intitulada "Entidades dizem que vão chamar a polícia contra médicos de Cuba"32. A notícia não se baseou em nenhum fato concreto, mas em suposições, endossada pelo verbo "dizem que vão chamar a polícia”. Caracteriza-se, segundo Fontcuberta ${ }^{33}$, como um não acontecimento que implica transformar em notícia um fato que 
Quadro 1. Valores-notícia de seleção (ordem alfabética).

\begin{tabular}{|c|c|}
\hline $\begin{array}{l}\text { Categorias de valores- } \\
\text { notícia de seleção }\end{array}$ & Conceito \\
\hline Conflito & $\begin{array}{l}\text { Esta categoria, bastante valorizada pela mídia, agrega fatos relacionados a guerras, } \\
\text { rivalidades, disputas, brigas, greves e reivindicações. }\end{array}$ \\
\hline Conhecimento & $\begin{array}{l}\text { Relacionado a descobertas, invenções e pesquisas: bastante utilizado nas seções de } \\
\text { ciência e de saúde que centram sua linha editorial na cobertura científica valorizando } \\
\text { a descoberta de um novo medicamento e/ou tratamento de determinada doença. }\end{array}$ \\
\hline Governo & $\begin{array}{l}\text { Concentra fatos relacionados a temas de interesse nacional, decisões e medidas } \\
\text { governamentais, inaugurações de instituições públicas, eleições, viagens e } \\
\text { pronunciamentos de representantes do governo. }\end{array}$ \\
\hline Impacto & $\begin{array}{l}\text { Traz a dimensão numérica como um fator que impacta na hora de selecionar um fato } \\
\text { para se tornar notícia: quanto mais pessoas são afetadas por determinado acontecimento, } \\
\text { mais chances há desse fato ser noticiado. Também faz parte dessa categoria o número } \\
\text { de pessoas envolvidas no fato; e grandes quantias de dinheiro. Há mais chances de ser } \\
\text { veiculado determinado roubo, por exemplo, se for de uma cifra expressiva. }\end{array}$ \\
\hline Justiça & $\begin{array}{l}\text { Compreende acontecimentos relacionados a julgamentos, denúncias, investigações, } \\
\text { apreensões, decisões judiciais e crimes. Este critério pode ter mais força se estiver } \\
\text { relacionado, por exemplo, ao critério de proeminência, considerando a notoriedade da } \\
\text { pessoa envolvida. }\end{array}$ \\
\hline Polêmica & $\begin{array}{l}\text { Este valor está relacionado a acontecimentos envolvendo escândalos e controvérsias. } \\
\text { É, dependendo do veículo, um critério também bastante valorizado na hora de decidir } \\
\text { o que será notícia. Em alguns casos, a própria mídia estimula controvérsias ainda não } \\
\text { existentes. Como exemplo, o caso de contrapor depoimentos de personalidades para } \\
\text { estimular uma controvérsia. }\end{array}$ \\
\hline Proeminência & $\begin{array}{l}\text { Está relacionada com a notoriedade do ator envolvido, sua importância social: se é } \\
\text { alguém da elite e/ou uma celebridade. Às vezes, não há nenhuma informação relevante } \\
\text { na notícia, mas o fato de um político, por exemplo, estar de passagem por determinada } \\
\text { cidade já é notícia. }\end{array}$ \\
\hline Proximidade & $\begin{array}{l}\text { Geográfica ou cultural. Quanto mais próximo um acontecimento estiver do seu } \\
\text { público, mais fácil de ser publicado. }\end{array}$ \\
\hline Raridade & $\begin{array}{l}\text { Fazem parte desta categoria os fatos considerados incomuns, originais ou inusitados. } \\
\text { Aqueles que fogem à regra estabelecida socialmente. É um dos critérios considerados } \\
\text { clássicos do jornalismo cuja premissa é que, quanto mais um acontecimento se desvia } \\
\text { do padrão, mais chances tem de se tornar notícia. }\end{array}$ \\
\hline Tragédia/Drama & $\begin{array}{l}\text { Aqui compreendem as catástrofes, acidentes, risco de morte e morte, violência/ } \\
\text { crime, suspense e emoção e interesse humano. Outro critério que agrega mais valor a } \\
\text { esta categoria é se estiver o de impacto, por exemplo, um acidente envolvendo várias } \\
\text { pessoas, ou mesmo o de proeminência, a morte de alguém da elite ou uma celebridade. }\end{array}$ \\
\hline
\end{tabular}

Fonte de informação: Silva ${ }^{20}$.

Quadro 2. Valores-notícia de construção - (ordem alfabética).

\begin{tabular}{|l|l|}
\hline $\begin{array}{l}\text { Categorias de valores- } \\
\text { notícia de construção }\end{array}$ & $\begin{array}{l}\text { Conceito } \\
\text { Consonância }\end{array}$ \\
$\begin{array}{l}\text { A faculdade de enquadrar um acontecimento em enquadramentos previamente } \\
\text { pré-imagem mental; reforça estereótipos. }\end{array}$ \\
\hline Dramatização & $\begin{array}{l}\text { O potencial de dramatização da história; reforço dos aspectos críticos, dramáticos e } \\
\text { conflituosos dos fatos. }\end{array}$ \\
\hline Personalização & $\begin{array}{l}\text { O potencial de personalização da história; tendência a apresentar as notícias como } \\
\text { frases em que existe um sujeito; como uma consequência das ações dessas pessoas. }\end{array}$ \\
\hline Simplificação & $\begin{array}{l}\text { Quanto menos ambígua e mais direta, mais possibilidades tem a notícia de ser } \\
\text { publicada; reduzir a natureza polissêmica do acontecimento. Clichês e estereótipos } \\
\text { são úteis. }\end{array}$ \\
\hline
\end{tabular}


não se produziu nem está previsto quando vai se produzir. Para o autor, a mídia cada vez mais utiliza informações baseadas em especulação, ganhando espaço em editorias representativas como Nacional, Internacional e Economia.

O outro grupo de chamadas enfocou a prestação de serviços (13 chamadas). A maioria centrou-se em fatos ocorridos no Estado de São Paulo, como a redução de leitos para dependentes químicos pela prefeitura e o programa estadual para internação compulsória de dependentes de crack. Em relação a essa categoria, o Hospital de Clínicas de SP foi a instituição hospitalar mais presente, com destaque em termos de atendimento e procedimentos cirúrgicos: "Em caso inédito, $\mathrm{HC}$ retira cisto gigante por corte no umbigo" ${ }^{34}$. Todavia, não houve referência ao fato de ser um procedimento realizado pelo sistema público de saúde.

Um dos órgãos do Ministério da Saúde mais presentes foi a Agência de Vigilância Sanitária (Anvisa), enfocando suas ações, principalmente a liberação ou a restrição de medicamentos, cigarros, mas também pontuando posicionamentos da Agência, como "Célula-tronco de cordão não é seguro de vida, alerta Anvisa" ${ }^{35}$. Diferente de alguns títulos em que outros atores "dizem", a Anvisa aparece como um ator mais valorizado como mostram alguns verbos: defende, libera, aprova, manda barrar, flexibiliza e alerta.

No El País, predominaram as notícias relacionadas à prestação de serviço (Tabela 2), como no caso do título "Hace siete meses que estoy tuerta" [Faz sete anos que estou torta ${ }^{36}$, acompanhado de um resumo que apresentava o número total de pessoas nas listas de espera por cirurgia. Essa chamada estruturou-se a partir de um enfoque individual sobre o relato de um caso para ampliar para o impacto que o aumento na lista de espera poderia representar para os usuários do SNS.

O segundo tópico mais presente foi sobre a privatização da saúde pública, com ênfase nas demissões, manifestações contra esse processo e o impacto no acesso aos serviços de saúde, como na chamada "La privatización de la sanidad en Madrid causa 322 dimisiones" [A privatização da saúde em Madri causa 322 demissões $]^{37}$. A notícia se referia a um anúncio de demissão coletiva por parte dos gestores dos centros de saúde, contrários ao processo em curso de privatização de ambulatórios e hospitais. Apesar de a demissão partir dos gestores, como forma de pressionar o governo, o enfoque dado pelo título responsabilizou o processo de privatização por esse fato.
Tabela 1. Categorias temáticas presentes nas chamadas de capa da FSP em 2013.

\begin{tabular}{lcc}
\hline \multicolumn{1}{c}{ Categorias } & Número & Frequência \\
\hline Programa Mais Médicos & 48 & $48 \%$ \\
Prestação de serviços & 13 & $13 \%$ \\
Outros $^{\star}$ & 11 & $11 \%$ \\
Ações e medidas Anvisa & 10 & $10 \%$ \\
Planos de saúde e ANS & 6 & $6 \%$ \\
Falta de médicos & 5 & $5 \%$ \\
Aids/HIV & 3 & $3 \%$ \\
Mudanças de gestor & 2 & $2 \%$ \\
Gestão SUS & 2 & $2 \%$ \\
Total & 100 & $100 \%$ \\
\hline
\end{tabular}

Fonte de informação: elaboração própria.

* temas que apareceram somente uma vez.

Tabela 2. Categorias temáticas presentes nas capas do El País em 2013.

\begin{tabular}{lrr}
\hline \multicolumn{1}{c}{ Categorias } & Número & Frequência \\
\hline Prestação de serviços & 9 & $23,07 \%$ \\
Privatização da saúde & 8 & $20,51 \%$ \\
Crise saúde pública & 5 & $12,82 \%$ \\
Financiamento farmacêutico & 5 & $12,82 \%$ \\
Outros $^{*}$ & 4 & $10,25 \%$ \\
Fechamento de urgências & 3 & $7,70 \%$ \\
Gasto sanitário & 3 & $7,70 \%$ \\
Irregularidades gestão & 2 & $5,13 \%$ \\
Total & 39 & $100 \%$ \\
\hline Fonte de informação: elaboração própria. & &
\end{tabular}

* temas que apareceram somente uma vez.

Para Ruane et al..$^{38}$, já ocorria um progressivo desmantelamento do SNS e, com o decreto de 2012, o processo de privatização se acelerou de acordo com a estratégia neoliberal vigente na Espanha. É relevante destacar ainda que as notícias relacionadas a outras categorias, como gastos sanitários, prestação de serviços e crise na saúde pública, também estavam relacionadas às mudanças desencadeadas a partir desse decreto, como na chamada "Los recortes en sanidad disparan cifras record las listas de espera" [Os recortes na saúde disparam em cifras recordes as listas de espera]. Os achados dialogam com os encontrados por Revuelta e Oliveira ${ }^{15}$. Os autores verificaram que a informação sobre saúde veiculada nos jornais espanhóis, entre eles o El Pais, se concentrava em um grupo muito reduzido de temas, encabeçando esse rol os relacionados ao 
SNS. Também $\operatorname{Costa}^{16}$ constatou que notícias relacionadas a políticas sanitárias predominaram na cobertura sobre saúde em jornais da Comunidade Autônoma da Galícia.

Ao comparar se as chamadas da Folha [Referência ao "SUS", "Sistema Único de Saúde", "rede pública", "saúde pública", "sistema de saúde" ou a palavra "público (a)", quando se referia a algum serviço de saúde] e do El País [Referência ao "SNS", "Sistema Nacional de Salud", "sistema sanitário", "salud pública", ou a palavra "público(a)", quando se referia a algum serviço de saúde] estabeleceram alguma relação direta com os sistemas públicos de saúde de seus respectivos países, só 17\%, no caso da Folha, se enquadraram nesse quesito em contraposição com o El País, que foi de $56,4 \%$. Os dados da Folha sugerem que grande parte dessa cobertura pareceu descolada do sistema público de saúde e, ao não relacionar as ações e programas como pertencentes ao SUS, contribuiu para a invisibilidade do sistema, conforme também identificado por Machado ${ }^{14}$.

\section{Valores-notícia nas capas de FSP e El País}

A produção jornalística se alimenta e, ao mesmo tempo, alimenta o cotidiano. A sedimentação do que se convenciona ser os critérios de noticiabilidade colabora para que se escolham, entre vários fatos, aqueles que podem ser transformados em notícia, "conferindo a esses estratos do real ou status de realidade" 39 . Os critérios de noticiabilidade colaboram para a construção social do que se entende por realidade.

Ao analisar os valores-notícia utilizados pelos dois jornais, verificamos que, das nove categorias de valores-notícia de seleção, os jornais investigados compartilham oito delas, entretanto, com frequência bastante diversa, conforme especificado na Tabela 3. O governo foi um valor-notícia constante nos dois veículos. Na Folha, a maioria das chamadas estava relacionada a decisões e medidas, mais especificamente no que se referia ao governo federal. No El País, o governo também foi um valor-notícia expressivo. Esses achados vão ao encontro do trabalho realizado por Gans ${ }^{40}$. $\mathrm{O}$ autor concluiu que as notícias que dominaram a cobertura de telejornais e revistas americanas estavam ligadas a assuntos do governo. Elas versavam sobre conflitos e desacordos; decisões e propostas governamentais e cerimônias; e pelas mudanças de cadeiras nos cargos públicos. O presidente dos EUA, por exemplo, sempre foi notícia, independentemente de ter feito algo significativo ou não.
Tabela 3. Comparativo dos valores-notícia de seleção nos jornais Folha de São Paulo e El País.

\begin{tabular}{lrr}
\hline $\begin{array}{c}\text { Valores-notícia } \\
\text { de seleção }\end{array}$ & $\begin{array}{c}\text { Folha de São Paulo } \\
\text { (100 chamadas) }\end{array}$ & $\begin{array}{c}\text { El País } \\
\text { (39 chamadas) }\end{array}$ \\
\hline Governo & $53 \%$ & $30,77 \%$ \\
Polêmica & $21 \%$ & $7,70 \%$ \\
Proeminência & $9 \%$ & $2,56 \%$ \\
Impacto & $5 \%$ & $20,20 \%$ \\
Raridade & $5 \%$ & $2,56 \%$ \\
Conflito & $3 \%$ & $12,82 \%$ \\
Conhecimento & $2 \%$ & 0 \\
Justiça & $1 \%$ & $7,70 \%$ \\
Tragédia/drama & $1 \%$ & $10,25 \%$ \\
Total & $100 \%$ & $100 \%$ \\
\hline
\end{tabular}

Fonte de informação: elaboração própria a partir de $\operatorname{Silva}^{20}$.

Algeri $^{41}$, ao analisar as capas de dois jornais locais de Santa Catarina, constatou que o subitem com maior percentual foi o de decisões e medidas governamentais, concluindo que esses jornais foram pautados principalmente por notícias oficiais, assessorias de imprensa e informações das prefeituras e Câmaras de Vereadores. Já Franzon $^{42}$, ao analisar as chamadas do Jornal Nacional e do Jornal da Cultura de SP, concluiu que ambos deram destaque aos acontecimentos ligados à proeminência, ao governo e à justiça.

Entretanto, diferente da Folha, em que as decisões ou as ações do governo ganharam força para serem lançadas à capa do jornal, o El País trouxe as ações governamentais quando estas estavam principalmente agregadas a outro valor-notícia, o impacto. O jornal veiculou notícias endossadas por números expressivos que envolveram uma quantidade grande de pessoas afetadas pelos acontecimentos, como no título "Las urgências rurales cierran para 100.000 castellano -manchegos" [As urgências rurais fecham para 100 mil castellomanchegos (cidadãos que nasceram na comunidade de Castilla la Mancha) $]^{43}$.

Para Traquina ${ }^{21}$, os jornalistas atribuem importância às notícias que dizem respeito a um número elevado de pessoas envolvidas, sendo assim maior a notabilidade desses acontecimentos. Rojo ${ }^{44}$ salienta que o valor impacto mostra-se determinante nas notícias que descrevem acontecimentos com efeitos, influência e consequências importantes. Para o autor, esse é o caso de fatos que contam com um número elevado de pessoas afetadas por um problema de saúde ou por uma medida política em matéria de saúde. 
Essa dimensão do impacto que uma medida política em saúde pode trazer para a sociedade esteve mais presente no El País do que na Folha de São Paulo. O jornal espanhol enfocou mais os fatos na perspectiva da população do que no caso da Folha, destacando as manifestações contrárias à privatização da saúde: "Miles de personas protestan en varias ciudades por los recortes" [Milhares de pessoas protestam em várias cidades pelos recortes $]^{45}$. A Folha, mesmo com a maioria das chamadas relacionadas a um programa de governo que se mostrava como uma alternativa para levar médicos onde não havia, não trouxe a população para suas capas. Como não foi contemplada nos títulos, linhas de apoio ou nos resumos, o jornal não trouxe como essas medidas iriam representar ou impactar as pessoas que seriam diretamente afetadas. Chama atenção a sua ausência nas capas do jornal se partimos da premissa, como destacam Souza e Bahia ${ }^{46}$, de que um dos componentes mais importantes de qualquer sistema público de saúde é a população, porque demonstra o quanto esse sistema é capaz de resolver os seus problemas.

Essa não legitimação dos usuários demonstra que, na cobertura da Folha, estes não foram considerados como vozes importantes sobre o sistema público. É relevante ainda refletir para qual público esses jornais se destinam ou se comunicam. A Folha tem, na versão impressa nacional, como público leitor majoritariamente as classes B $(44 \%)$ e C $(37 \%)^{47}$. Para Charaudeau ${ }^{48}$, cada meio de comunicação faz escolhas relacionadas ao seu público, considerando questões como a classe social e a faixa etária, mas o autor lembra que esses aspectos compõem uma ideia do que seria esse público que, entretanto, se mostra diverso e mutável. Nessa perspectiva, é possível inferir que os leitores da Folha não são vistos como um público usuário dos serviços públicos de saúde, o que não significa efetivamente que não o sejam. Conforme destacam Teixeira et al. ${ }^{49}$, mesmo aqueles que acreditam que não utilizam o SUS, porque pagam planos de saúde, são usuários desse sistema por usufruírem de ações epidemiológicas, sanitárias e ambientais realizadas pelos serviços públicos de saúde.

Quem esteve presente nas chamadas da Folha foram as instituições, como o Ministério da Saúde, os conselhos federais e regionais de medicina e a Anvisa. Diferente do que pode ocorrer na Espanha, que - apesar das deficiências atuais do SNS - o sistema é menos estratificado e mais abrangente, com uma cobertura de $95 \%$ da população ${ }^{50}$. É possível supor que o El País ainda fala para um público usuário do sistema sanitário à medida que este ganha destaque nas chamadas: "Me negaron el antitumoral por caro" ${ }^{51}$.

Segundo Camacho ${ }^{52}$, nos últimos 30 anos, os meios de comunicação na Espanha têm aumentado sua atenção à temática sanitária. Com a chegada da democracia, os meios começaram a se interessar pela reforma sanitária, alcançando o seu apogeu, na década de 1990, quando a informação sanitária se transforma, segundo Jurado Salván ${ }^{53}$, em acontecimento sanitário. Nesse momento, o interesse volta-se para as pautas relacionadas à lista de espera e às falhas na assistência, como reflexo de um período de deteriorização política dos últimos anos do governo socialista. Para García-Latorre e Gobantes-Bilbao ${ }^{22}$, a saúde é um dos pilares do Estado de Bem-Estar Social espanhol [A partir dos anos 1980, o Estado de Bem -Estar Social se estrutura na Espanha, em torno de quatro áreas principais: saúde, educação, segurança social e serviços sociais.], contando, por isso, com um alto valor-notícia. Como desperta o interesse da população, é um conteúdo constante na cobertura jornalística. Em comparação com os outros países da União Europeia, a Espanha tem gasto social médio-baixo com altos déficits na qualidade de grande parte dos serviços, exceto no que se refere à saúde ${ }^{53}$. Matos-Silveira ${ }^{54} \mathrm{faz}$ uma ressalva em relação às mudanças resultantes do decreto, de 2012, que impactaram o acesso dos estrangeiros ao sistema e diminuíram os investimentos na área.

Segundo García-Latorre e Gobantes-Bilbao ${ }^{22}$ :

No resulta extraño que la Salud Pública sea un área de interés periodístico, ya que cubre temas más cercanos a la calle y a los ciudadanos-lectores [...] dado que afectan directamente a la población y lo hacen también em mayor número que el descubrimiento de un gen o una nueva terapia.

No Brasil, o SUS também surge como uma política de Bem-Estar Social, quando a saúde passa a ser um direito ${ }^{48}$. Para Castellanos ${ }^{55}$, o caso brasileiro comporta especificidades: a sua formação e implantação coincidem com a onda neoliberal nos países da América-Latina, pela forte crise econômica mundial e pela disputa das elites e do capital financeiro para definir quais seriam as políticas econômicas e sociais. Tais fatores dificultaram uma real sedimentação do Estado de Bem-Estar Social brasileiro.

Outro valor-notícia bastante recorrente na Folha foi a polêmica, principalmente abordando questões e embates relacionados ao programa Mais Médicos, o tema mais noticiado. É importante considerar, entretanto, que o próprio jornal 
pôde, a partir desse enfoque, construir ou mesmo alimentar essas controvérsias. Ponte ${ }^{56}$, ao analisar notícias que cobriram eventos sobre o bem-estar das crianças europeias, identificou vários valores-notícia, mas a polêmica foi um dos atributos mais utilizados. No caso do El País, entretanto, esse valor esteve pouco presente ou foi um valor secundário.

Os valores-notícia devem ser entendidos levando em consideração os modelos sobre a sociedade e os seus consensos ${ }^{57}$. São mais do que uma listagem de atributos das notícias porque ajudam a construir a sociedade como consenso, marcando os limites entre o que é considerado "normal" ou "desviante", o que requer um conhecimento consensual sobre a sociedade ${ }^{18}$. Para Curto $^{58}$, seriam as convicções, os acontecimentos e as expectativas compartilhadas da vida diária que fundamentam nosso sentido de realidade. $\mathrm{E}$ seria esse marco de pressupostos e expectativas da vida cotidiana e que dão sentido à noticiabilidade.

Campos et al. ${ }^{59}$ afirmam que a noticiabilidade de um acontecimento apoia-se, ao mesmo tempo, em dois suportes: de um lado, nas expectativas sociais a ele relacionadas e, de outro, segundo as especificidades da produção noticiosa.

Para os autores ${ }^{59}$, funcionam como:

Decodificadores sociais dos fatos fora do comum, invulgares, imprevisiveis, conflituosos e problemáticos, os absorvem e constroem, ao mesmo tempo, o consenso social. A sociedade necessita entender o seu entorno, cada vez mais segmentado, especializado e complexificado.

\section{Estratégias do El País e da Folha na construção das notícias}

Os jornais estudados adotaram estratégias distintas na forma como apresentaram suas notícias. Nos voltamos aqui para as chamadas que mais expressaram as características e as qualidades valorizadas durante a elaboração da notícia.

A Folha, ao enfocar prioritariamente a participação dos médicos vindos de Cuba, recorreu ao valor-notícia simplificação, reduzindo, de certa forma, o programa aos médicos cubanos ou mesmo aos "médicos de Dilma", como na manchete "Prefeitos demitirão médicos locais para receber os de Dilma" ${ }^{60}$. Foi possível ainda constatar que, no decorrer da cobertura, o programa perdeu a sua contextualização simplificando a abordagem adotada. Para Ericson et al. ${ }^{61}$, quanto mais um evento é desprovido de ambiguidade e de complexidade, mais possibilidades tem a notícia de ser notada e compreendida, o que sustentaria esse tipo de escolha na elaboração das notícias. Segundo Traquina ${ }^{21}$, é a partir desse enfoque que decorrem as ideias feitas, os estereótipos e os clichês.

O jornal El País utilizou outras estratégias na forma como destacou e apresentou suas notícias, como os valores de personificação e de dramatização, para construir a sua relação com o leitor. A personificação é considerada um valor fundamental no discurso jornalístico ${ }^{62}$. Por personalizar, entende-se valorizar as pessoas envolvidas no acontecimento: acentuar o fator pessoa. $\mathrm{O}$ jornal lançou mão das falas dos entrevistados nos títulos das chamadas, como nos exemplos: "No se imagina la catástrofe que viene" [Não se imagina a catástrofe que está vindo] ${ }^{51}$.

A personalização é uma estratégia para seduzir o leitor, fazer com que ele se identifique porque as pessoas se interessam por pessoas. "Quanto mais personalizado é um acontecimento, mais possibilidades tem a notícia de ser notada, pois facilita a identificação desse fato em termos "negativo" ou "positivo"21. Outro valor-notícia foi a dramatização, recorrendo a um apelo emocional, enfatizando as notícias com carga dramática ${ }^{62}$. No caso do título já citado, "Hace siete meses que estoy tuerta"35, o El País recorreu, além da personalização, à dramatização, ao enfocar o drama humano, trazendo para a capa elementos que poderiam sensibilizar os seus leitores. A personalização e a dramatização já foram identificados como recursos associados por Ericson et al. ${ }^{61}$. Todavia, não foram identificados na cobertura da Folha sobre o tema investigado.

A notícia deve estar em consonância com as normas, os valores e as atitudes socialmente compartilhados, estando implicadas as opiniões e as atitudes preexistentes. É de compreensão e de aceitação mais fácil a notícia consonante com atitudes de jornalistas e leitores, ou seja, com o consenso ideológico de uma sociedade e de determinada cultura ${ }^{20,50}$.

Esse valor tende a alocar um acontecimento em enquadramentos já existentes, encaixando as notícias novas em um molde já conhecido, em uma pré-imagem mental. Para Ericson et al. ${ }^{61}$, essa pré-imagem mental pode contribuir para a sedimentação de estereótipos na cobertura midiática. Para os autores ${ }^{61}$, o significado de um acontecimento pode ser julgado antes, ao ponto de o repórter visualizar o que vai acontecer e produzir uma notícia totalmente previsível, construindo um conhecimento estereotipado.

No caso da saúde, os comportamentos e as atitudes em relação ao sistema público, confor- 
me destaca Silva ${ }^{62}$, não são definidos apenas pelas características da própria rede de cuidados que compõe o sistema, mas também pelos valores culturais de determinado entorno social: a configuração do sistema pode ser ela própria a expressão dos valores dominantes em uma dada sociedade, em relação aos quais os meios de comunicação assumem um papel relevante na sua disseminação e legitimação.

Nos interessa refletir sobre quais são esses moldes que podem sedimentar estereótipos em relação à cobertura dos sistemas públicos de saúde investigados. Paim ${ }^{63}$ identifica que há quatro SUS que convivem entre eles: o formal (assegurado pela legislação, ainda que distante do cotidiano dos cidadãos e dos trabalhadores de saúde); para pobres (vinculado à ideologia liberal e derivado das políticas focalizadas onde a falta de recursos é a regra); o real (subordinado aos desígnios das áreas econômicas, onde viceja o pragmatismo, conciliando interesses clientelistas, partidários, corporativos e econômicos) e o democrático (concebido pela RSB, vinculado a uma democracia substantiva comprometida com os direitos da cidadania, com a participação política e com os valores da igualdade, solidariedade e emancipação). Podemos supor que a pré-imagem do SUS possivelmente esteja relacionada a um sistema para pobres, e não como um direito do cidadão. Tal percepção vai ao encontro de Tavares et al. ${ }^{64}$. A partir de entrevistas aleatórias com cidadãos, os autores constataram que a concepção recorrente sobre o modelo de saúde pública era do SUS como oferta de serviços para a população carente" 64 .

No diário espanhol, percebemos que a narrativa noticiosa foi construída com o enfoque centrado nos problemas e nas dificuldades enfrentados pelo sistema. Cada nova história era encaixada nesse mesmo molde.

\section{Considerações finais}

Este estudo buscou encontrar similitudes e diferenças na cobertura analisada. Verificamos que a Folha trouxe mais chamadas que o El País, todavia seu enfoque centrou-se precisamente em um evento, o Programa Mais Médicos, com seus desdobramentos. No El País, o tema principal foi a privatização da saúde, mas composta de vários eventos, como as manifestações contrárias, as demissões de funcionários e gastos sanitários, entre outros. Os critérios que nos levaram a selecionar o ano de 2013 para análise na Folha - os 25 anos da constituição, que garantiu o direito à saúde, $\mathrm{e}$ as reivindicações sobre a saúde presentes nas manifestações de junho - ambos não subsidiaram as chamadas. $\mathrm{O}$ jornal chegou a trazer as manifestações para as capas, mas sem enfocar a saúde. $\mathrm{O}$ direito à saúde também não foi considerado uma angulação relevante para compor suas capas.

No El País, nossa escolha se guiou pelas mudanças ocorridas em decorrência do decreto-lei, publicado em 2012, que impôs recortes e restrições ao acesso à saúde. A cobertura do jornal espanhol esteve mais alinhada ao impacto que tal medida poderia acarretar à população, trazendo as repercussões e os desdobramentos em decorrência dessas mudanças.

Constatamos ainda que os jornais utilizaram recursos diversos no processo de elaboração da notícia. A Folha lançou mão da simplificação em relação à abordagem adotada sobre o Programa Mais Médicos que, em certa medida, se reduziu aos "médicos cubanos", ou aos "médicos da Dilma". O El País investiu na personalização e na dramatização para sensibilizar os leitores ao trazer os usuários e os profissionais de saúde para as suas capas em que, em muitos casos, o pano de fundo era o processo de privatização da saúde.

Cabe ainda destacar que outros estudos devem ser realizados incluindo novos formatos midiáticos, analisando se, nessas dinâmicas, os processos de seleção e construção das notícias sofrem mudanças e de que forma se adaptam em relação às tecnologias disponíveis. 


\section{Colaboradores}

A Langbecker produziu, analisou os dados e escreveu o artigo. MEP Castellanos e D Catalán -Matamoros fizeram revisão, correção e sugestões no manuscrito.

\section{Agradecimentos}

AL agradece à Universidad Carlos III de Madrid pela estância doutoral e ao professor Daniel Catalán-Matamoros pelos ensinamentos e pelo companheirismo.

À Coordenação de Aperfeiçoamento de Pessoal de Nível Superior (Capes) pelo financiamento de bolsa sanduíche. O presente artigo é resultado da tese de doutorado do primeiro autor.

\section{Referências}

1. Arakawa T, Magnabosco GT, Lopes LM, Arnaez MAA, Gavín, MAO, Gallardo, MPS, Monroe AA, Villa, TCS. Avaliação de desempenho de Programas de Controle de Tuberculose no contexto brasileiro e espanhol: uma revisão integrativa da literatura. Cien Saude Colet 2015; 20(12):3877-3889.

2. Noronha JC, Lima LD, Machado CV. O Sistema Único de Saúde - SUS. In: Giovanella L, Escorel S, Lobato LVC, Noronha JC, Carvalho AI, organizadores. Políticas e sistema de saúde no Brasil. Rio de Janeiro: Fiocruz; 2012. p. 365-394.

3. Paim JS. O que é o SUS. Rio de Janeiro: Fiocruz; 2009.

4. Paim JS, Travassos C, Almeida C, Bahia L, Macinko J. O sistema de saúde brasileiro: história, avanços e desafios. Lancet 2011; SCS5708:11-31.

5. Martín MS. Ideas fuerza en salud pública. In: Cuesta U, Peñafiel C, Terrón JL, Bustamante E, Gaspar S, organizadores. Comunicación y salud. Madri: Dextra editorial, 2017. p. 229-250.

6. Pereira AMM, Lima LD, Machado CV. Descentralização e regionalização da política de saúde: abordagem histórico-comparada entre o Brasil e a Espanha. Cien Saude Colet 2018 23(7):2239-2251.

7. Añón CL. La titularidad del derecho a la salud en España. ¿Hacia un cambio de modelo? Rev de Bioética y Derecho 2014; (31):3-16.

8. López-Fernández LA, Millán JIM, Ajuria AF, Cerdà JCM, Suess A, Danet AD, Rodríguez MAP. ¿Está enpeligro la cobertura universal en nuestro Sistema Nacional de Salud? GacSanit 2012; 26(4):298-300.

9. Paim JS. O futuro do SUS. Editorial. Cad Saude Publica 2012; 28(4):612-613.

10. Cavalcante CC. Os sentidos do Sistema Único de Saúde na mídia impressa do Ceará: um estudo do jornal O Diário do Nordeste [dissertação]. Rio de Janeiro: Fiocruz; 2014.

11. Silva GM, Rasera EF. Desqualificação do SUS na Folha de São Paulo: construção discursiva de gestores e usuários. Psico 2013; 44(1):82-91.

12. Silva GM, Rasera EF. A construção do SUS: problema no jornal Folha de S. Paulo. Hist Cienc Saude Manguinhos 2013; 21(1):61-76.

13. Menegon VSM. Crise dos serviços de saúde no cotidiano da mídia impressa. Psico Soc 2008; 20 (esp):3240.

14. Machado IB. Percepções sobre o SUS: o que a mídia mostra e o revelado em pesquisa. In: Lerner K, Sacramento I, organizadores. Saúde e jornalismo: Interfaces contemporâneas. Rio de Janeiro: Fiocruz; 2014. p. 235250.

15. Revuelta G, Oliveira JM. La salud y la biomedicina en la prensa diaria. Una análisis de diez años. Periodista 2008; (11):55-67.

16. Costa SC. Medicina y salud en la prensa. Las noticias de salud en los principales diarios de Galicia. Rev Lat Comun Soc 2008; 11(63):15-21.

17. Valdivieso AP. La salud y su manipulación. Análisis de dos periódicos nacionales: El País y El Mundo. Rev Esp Comun Salud 2011; 2(1):13-23.

18. Álvarez EM. Análisis de los contenidos sanitários en prensa nacional: ABC y La Razón. Rev Esp Comun Salud 2011;2(1):3-12. 
19. Alazne YA, Idoia CM, Milagros RL. La saludenla prensa vasca. Análisis de contenido de la década 20012010. In: Actasdel IV Congreso Internacional Latina de Comunicación Social; La Laguna; 2012. p. 1-16.

20. Silva MP. Perspectivas históricas da análise da noticiabilidade. In: Silva G, Silva MP, Fernandes ML. Critérios de noticiabilidade: problemas conceituais e aplicações. Florianópolis: Insular; 2014. p. 25-38.

21. Traquina N. Teorias do jornalismo: porque as notícias são como são. Florianópolis: Insular; 2013.

22. García-Latorre FJ, Gobantes-Bilbao M. La información sanitaria autonómica en la prensa diaria: el caso de Aragón. Rev Esp Comum Salud 2014; 5(2):149-167.

23. Bardin L. Análise de conteúdo. Portugal: Edições 70; 2009.

24. Van Dijk TA. La noticia como discurso: comprensión, estructura y pro-ducción de lainformación. Barcelona: Paidós; 1990.

25. Alasina MR. La construcción de la noticia. $2^{\mathrm{a}}$ ed. Barcelona: Paidós; 1993.

26. Wolf M. Teorias da comunicação de massa. São Paulo: Martins Fontes; 1987.

27. Folha de São Paulo. Manual da Folha de São Paulo. 5a ed. São Paulo: Publifolha; 2011.

28. El País. Libro de Estilo del Diario El País. Madrid: Santillana Ediciones;2014.

29. Magno LD, Paim JS. Dos clamores das ruas aos rumores no congresso: uma análise da conjuntura recente da saúde no Brasil. RECIIS - Rev Eletron Comun Inf Inov Saude 2015; 9(4):1-14.

30. Caldeira AB. Chamada de capa: análise do gênero jornalístico com base na abordagem sócio-retórica de swales [dissertação]. Santa Catarina: Universidade do Sul de Santa Catarina; 2007.

31. Baccega MA. A construção do real e do ficcional. In Figaro R, organizador. Comunicação e análise do discurso. São Paulo: Contexto; 2013. p. 119-140.

32. Entidades dizem que vão chamar a polícia contra médicos de Cuba. Folha de São Paulo 2013; 24 ago.

33. Fontcuberta M. La noticia: pistas para percibir el mundo. Barcelona: Paidós; 1993.

34. Em caso inédito, HC retira cisto gigante por corte no umbigo. Folha de São Paulo 2013; 16 out.

35. Célula-tronco de cordão não é seguro de vida, alerta Anvisa. Folha de São Paulo 2013; 24 maio.

36. Hace siete meses que estoy tuerta. El País 2013; 28 ago.

37. La privatización de la sanidad en Madrid causa 322 dimisiones. El País 2013; 9 jan.

38. Ruane S, Bayle MS, Gurucelain JL, Palomo L, Lores ML, Llopis ES. Las cuestiones clave de la sanidad pública: un diagnóstico comparado de los Sistemas Públicos Sanitarios de España y el Reino Unido. Madrid: Fundación $1^{\circ}$ de maio/Colección Estudios; 2013.

39. Ferreira GM, Dalmonte EF. Web jornalismo, critérios de noticiabilidade e efeitos de sentido. Comun: veredas 2008; 7(7):117-135

40. Gans HJ. Decidingwhat's News: a study of CBS Evening News, NBC Nightly News, News week and Time. Illions: North Western University Press; 2004.
41. Algeri C. O local e o global: fatores que definem a pauto em dois jornais do oeste de Santa Catarina [dissertação]. Florianópolis: Universidade Federal de Santa Catarina; 2011.

42. Franzon E. Os valores-notícia em telejornais. In: III Curso de Especialização em Estudos de Jornalismo (lato sensu) da UFSC; 2004; Santa Catarina.

43. Las urgencias rurales cierran para 100.000 castellano -manchegos. El Pais 2013; 15 jan.

44. Rojo JAD. La polémica, las «buenas noticias» y las «malas noticias" como valores noticiosos predominantes en el discurso sobre la salud en tres diarios nacionales españoles: retórica y cultura en la información periodística sobre salud. Madrid: Ministerio de Ciencia e Innovación; 2009.

45. Miles de personas protestan en varias ciudades por los recortes. El País 2013; 24 fev.

46. Souza LEPF, Bahia L. Componentes de um Sistema de Serviços de Saúde: população, infraestrutura, organização, prestação de serviços, financiamento e gestão. In: Paim JS, Almeida-Filho N, organizadores. Saúde coletiva: teoria e prática. Rio de Janeiro: MedBook; 2013. p. 49-66.

47. Perfil do Leitor. Folha de São Paulo. [acessado 2017 Dez 20]. Disponível em: http://www.publicidade.folha.com.br/folha/perfil_do_leitor.shtml

48. Charaudeau P. Le discours d'information médiatique. Paris: INA; 1997.

49. Teixeira C, Souza LE, Paim JS. Sistema Único de Saúde (SUS): a difícil construção de um sistema universal na sociedade brasileira. In: Paim JS, Almeida-Filho N, organizadores. Saúde Coletiva - Teoria e Prática. Rio de Janeiro: Med Book; 2014. p. 121-137.

50. España. Ministerio de Sanidad, Servicios Sociales e Igualdad (MSSSI). Informe anual del Sistema Nacional de Salud 2013. Madrid: MSSSI; 2014.

51. No se imagina la catástrofe que viene. El País 2013; 15 jun.

52. Camacho I. Noticias sobre salud y medicina: mucho más que información. In: Camacho I, organizador. $L a$ especialización en el periodismo: formarse para informar. Zamora: Comunicación social; 2010. p. 145-165.

53. Jurado Salván E. Evolución de la información sanitaria en la prensa escrita durante la transición española. [tesis]. Madrid: Universidad Complutense de Madrid; 2003.

54. Matos-Silveira R. Trabajo Social en España: contextos históricos, singularidades y desafios actuales. Rev katálysis 2013; 16(n. esp):101-109.

55. Castellanos MEP. Right to healthcare and inequalities in public health system in Brazil: some vulnerabilities contexts. In: Bogalska-Martin E, Matteudi E, organizadores. The Social Question in the Global World. Cambridge: Scholar Publishing; 2018. p. 306-330.

56. Ponte C. Cobertura jornalística da infância: definindo a "criança internacional". Soc Prob Prát 2002; (38):6177.

57. Ponte C. Para entender as notícias: Linhas de análise do discurso jornalístico. Florianópolis: Insular; 2005.

58. Curto GA. La noticia, el cotidiano y el espejo de la ficción. CIC Cuad Inf Com 1996; (2):57-62. 
59. Campos MATF, Vieira CDD, Mota JAC. A infância sem segredos: a noticiabilidade jornalística do crime de exploração sexual de crianças e adolescentes. Interface (Botucatu) 2009; 13(30):17-29.

60. Prefeitos demitirão médicos locais para receber os de Dilma. Folha de São Paulo 2013; 30 ago.

61. Ericson RV, Baranek PM, Chan J. Visualizing seviance: a study of News organization. Toronto: University of Toronto Press; 1987.

62. Silva PA. A saúde nos Mass Media. Lisboa: Mundos Sociais; 2011.

63. Paim JS. O futuro do SUS. Cad Saude Publica 2012; 28(4):612-613.

64. Tavares FL, Laignier MR, Silva MZ, Daros RF, Lima RCD. O SUS que temos e a informação como estratégia de (in)visibilidade. Saude Debate 2003; 27(65):405-413.

Artigo apresentado em 09/03/2018

Aprovado em 21/12/2018

Versão final apresentada em 23/12/2018 